\title{
Improving discoverability of tephra data through development of data upload templates and collection tools using community-driven best practices recommendations
}

\author{
KRISTI L WALLACE ${ }^{1}$, MARCUS BURSIK ${ }^{2}$, SIMON \\ GORING $^{3}$, SAMUEL KODAMA ${ }^{4}$, STEVE KUEHN ${ }^{5}$, ANDREI \\ KURBATOV $^{6}$, KERSTIN A LEHNERT ${ }^{7}$, LUCIA PROFETA ${ }^{4}$, \\ SARAH RAMDEEN ${ }^{4}$ AND J. DOUGLAS WALKER ${ }^{8}$ \\ ${ }^{1}$ US Geological Survey \\ ${ }^{2}$ University at Buffalo \\ ${ }^{3}$ University of Wisconsin-Madison \\ ${ }^{4}$ Lamont-Doherty Earth Observatory, Columbia University \\ ${ }^{5}$ Concord University \\ ${ }^{6}$ University of Maine \\ ${ }^{7}$ Columbia University \\ ${ }^{8}$ University of Kansas \\ Presenting Author: kwallace@usgs.gov
}

Tephra is a unique volcanic product that plays an unparalleled role in understanding past eruptions, the long-term behavior of volcanoes, and the effects of volcanism on climate and the environment. Tephra deposits also provide spatially widespread, extremely high-resolution time-stratigraphic markers across a range of sedimentary settings and are used by many disciplines (e.g. volcanology, seismotectonics, climate science, archaeology, ecology, public health and ash impact assessment). In the last two decades, tephra studies have become more interdisciplinary in nature but are challenged by a lack of standardization that often prevents comparison amongst various regions and across disciplines. To address this challenge, the global tephra community has come together through a series of workshops to establish best practice recommendations for tephra studies from sample collection through analysis and data reporting. This new standardized framework will facilitate consistent tephra documentation and parametrization, foster interdisciplinary communication, and improve effectiveness of data sharing among diverse communities of researchers. One specific goal is to use the best practice guidelines to inform digital tool and data repository development. Here we report on 1) a new set of templates for tephra sample documentation, geochemical method documentation and data reporting using recommended bestpractice data and metadata fields, 2) a new tephra module added to StraboSpot, an open source geologic mapping and datarecording multi-platform software application, and 3) new implementations and cross-mapping of metadata requirements at SESAR (System for Earth Sample Registration) and EarthChem. Addition of tephra-specific fields to StraboSpot enables users to consistently collect and report essential tephra data in the field which is then automatically saved to an online data repository. A new tephra portal on the EarthChem website will allow users to follow simple workflows to register tephra samples at SESAR and submit microanalytical data to EarthChem. Usage of SESAR and EarthChem supports data management for researchers and 